\title{
Imaging Diagnosis of Ductal Carcinoma In Situ
}

\author{
Mihai Lesaru ${ }^{1,2 *}$, Carmen Lisencu ${ }^{3}$ \\ 'Department of Radiology and Medical Imaging, Clinical Institute "Fundeni", Bucharest, Romania \\ 2Department of Radiology and Medical Imaging, "Carol Davila" University of Medicine and Pharmacy, Bucharest, Romania \\ ${ }^{3}$ Breast Tumor Center, "Prof. Dr. Ion Chiricuta" Institute of Oncology, Cluj-Napoca, Romania
}

${ }^{*}$ Corresponding author: Mihai Lesaru, MD Department of Radiology and Medical Imaging "Fundeni" Clinical Institute Bucharest, Romania

E-Mail:m.lesaru@gmail.com

\section{Rezumat}

Carcinomul ductal in situ (CDIS) a devenit un subiect de interes după introducerea programelor de screening mamografic. Aproape 90\% din CDIS sunt detectate prin mamografie, în particular cea de screening, aceasta rămănând principala metodă imagistică pentru CDIS. Evaluarea mărimii tumorii realizată prin metode imagistice a ajutat chirurgul să utilizeze chirurgia conservatoare mai frecvent, comparativ cu mastectomia, cu rezultate oncologice sigure. În cele mai multe situații mamografia poate fi considerată suficientă pentru a determina corect extensia bolii. Totuşi, imagistica prin rezonanță magnetică (IRM) s-a dovedit mai precisă în evaluarea extensiei bolii, în special la femeile tinere. Ecografia nu este metoda de elecție pentru CDIS dar pare să îşi aducă contribuția în detectarea semnelor specific ale diagnosticului şi ale extensiei tumorii. Revederea literaturii este trecută prin lumina propriei experiențe.

Cuvinte cheie: CDIS, mamografie, ecografie, rezonanță magnetică

\section{Abstract}

DCIS became a topic of interest mainly after the onset of mammography screening programs. Almost 90\% of DCIS are detected by mammography, in particular screening, and this remains the main imaging method for DCIS. The evaluation of tumor size made by imaging methods helped surgeons to use conservative breast surgery more frequently, instead of mastectomy, with safe oncological results. In many situations mammography could be considered enough to determine the correct extension of 
the disease. However, magnetic resonance imaging (MRI) proved to be more accurate in the evaluation of the extension of the disease, especially in young women. The ultrasound is not the method of choice for DCIS but seems to bring its contribution in detecting specific signs of the diagnosis and the tumor extension. The review of the literature is passed through the light of authors' own experience.

Key words: DCIS, mammography, ultrasound, magnetic resonance imaging

\section{Introduction}

DCIS incidence and prevalence have steadily increased in the last years, mostly related to mammography screening programs becoming more widely adopted worldwide (1-9). Imaging methods in DCIS intend to detect the specific signs for DCIS, determining the size of the tumor in order to have an appropriate oncological excision, and making possible a correct follow-up after excision in order to detect residual lesions or relapse. The algorithm of imaging investigation is related to the age of the patient and clinical signs. For women after 40 years, where DCIS occurs more frequently, the starting imaging method is mammography, completed for dense breasts with ultrasound and MRI. For women under 40 years the first imaging methods recommended are ultrasound, completed with mammography when microcalcifications are suspected, and MRI. Clinical signs, like palpable lump and bloody nipple discharge, are rarely seen in our days, when most of the DCIS are occult when detected.

\section{Mammography}

DCIS is, by definition, an intraductal proliferation and imaging methods identify the corresponding aspects that reflect the pathological changes. The typical change associated with DCIS is the presence of calcifications, result of intraductal necrosis in the case of high-grade DCIS or secretory calcifications in low and intermediate grade DCIS. Consequently, mammography detects different types of calcifications. In high-grade
DCIS the calcifications, due to the intraductal necrosis, are linear, with ductal orientation, irregular contours, sometimes Y shape. These are the so-called comedonecrosis calcifications (Fig. 1), associated with high-grade DCIS in $70 \%$ of cases (12). In intermediate and low-grade DCIS, the calcifications are rather amorphous, punctate, with ductal distribution or triangular shape clusters. The ability to detect these macrocalcifications helped establish mammography as a screening method for breast cancer. Almost 90\% of all DCIS are diagnosed with the aid of screening mammography. Before the widespread adoption of screening programs, DCIS accounted for about $5 \%$ of all breast cancers (10). Since then, eight trials evaluating the impact of screening mammography proved that DCIS represents about $20 \%$ of all detected cancers through

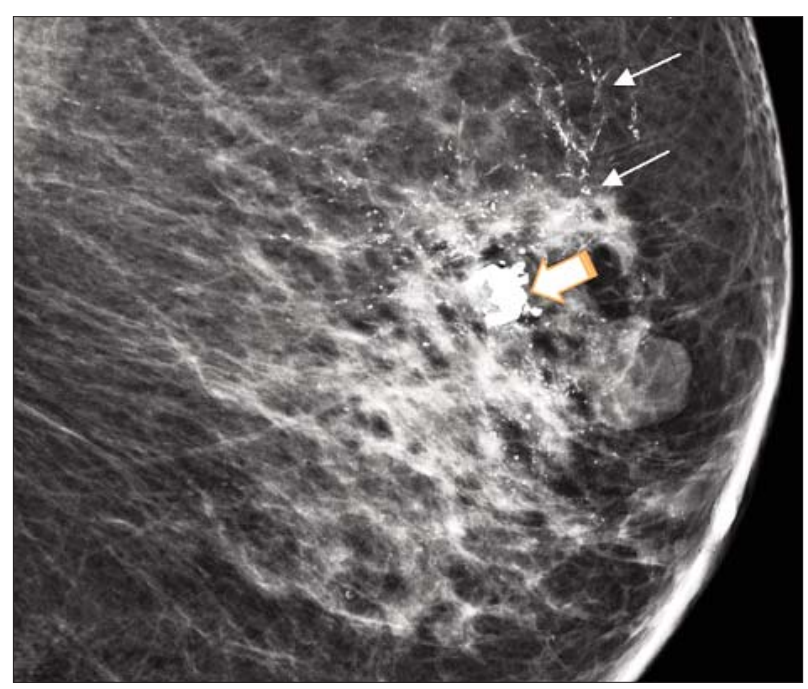

Figure 1. Comedonecrosis type calcifications (thin arrows) spread in the breast in triangular distribution (BIRADS 5 lesion). Note the typically benign calcification (thick arrow) 
screening (2). DCIS is becoming mainly an unintended finding in breast cancer screening (11). It is estimated that 1 in 1300 screening mammograms will detect a DCIS. However, not all DCIS are identified by microcalcifications and mammographic sensitivity ranges from 27 to $80 \%$. It is estimated that $6-23 \%$ of DCIS cases remain undetected on mammography related to the absence of calcifications (13). Additionally, not all calcifications, especially the amorphous one, are signs for DCIS. In many situations punctate and amorphous calcifications are signs for the histologically B3 lesions, which could coexist with low-grade DCIS. The B3 category includes lesions with uncertain malignant potential, which are the main differential diagnostic for DCIS, mainly the low-grade one, and include atypical ductal hyperplasia $(\mathrm{ADH})$, flat epithelial atypia (FEA), lobular neoplasia (LN), and papillary lesions.

The density of the breast is the main characteristic that influences the sensitivity of the mammography. This sensitivity is lower in dense breasts and higher in fatty breasts. In dense breast the microcalcifications could be missed, especially the amorphous and punctate ones, due to the very opaque background.
The sensitivity is higher if tomosynthesis is added (Fig. 2). In fatty breasts practically all the microcalcifications could be seen due to the natural structural contrast, and consequently the extension of the disease can be appreciated accurately enough by mammography only.

The calcifications can be present alone (the most frequent situation for the pure DCIS) or associated with masses, architectural distortion, and focal asymmetries.

Mammography is the method of choice for the follow-up after conservative breast surgery. The first mammography could be done for the operated breast within the first month after excision to check for residual microcalcifications. After that a yearly mammography is recommended.

\section{Ultrasound}

Ultrasound is not the recommended method for the diagnostic of DCIS. However, Baek et al. (21) demonstrated that ultrasound can see $96,4 \%$ of the pathology proven DCIS. In a large multicentric retrospective study, Takanori W et al. (14) showed that the most frequent findings in DCIS were hypoechoic areas in the mammary gland $(48.6 \%)$, followed

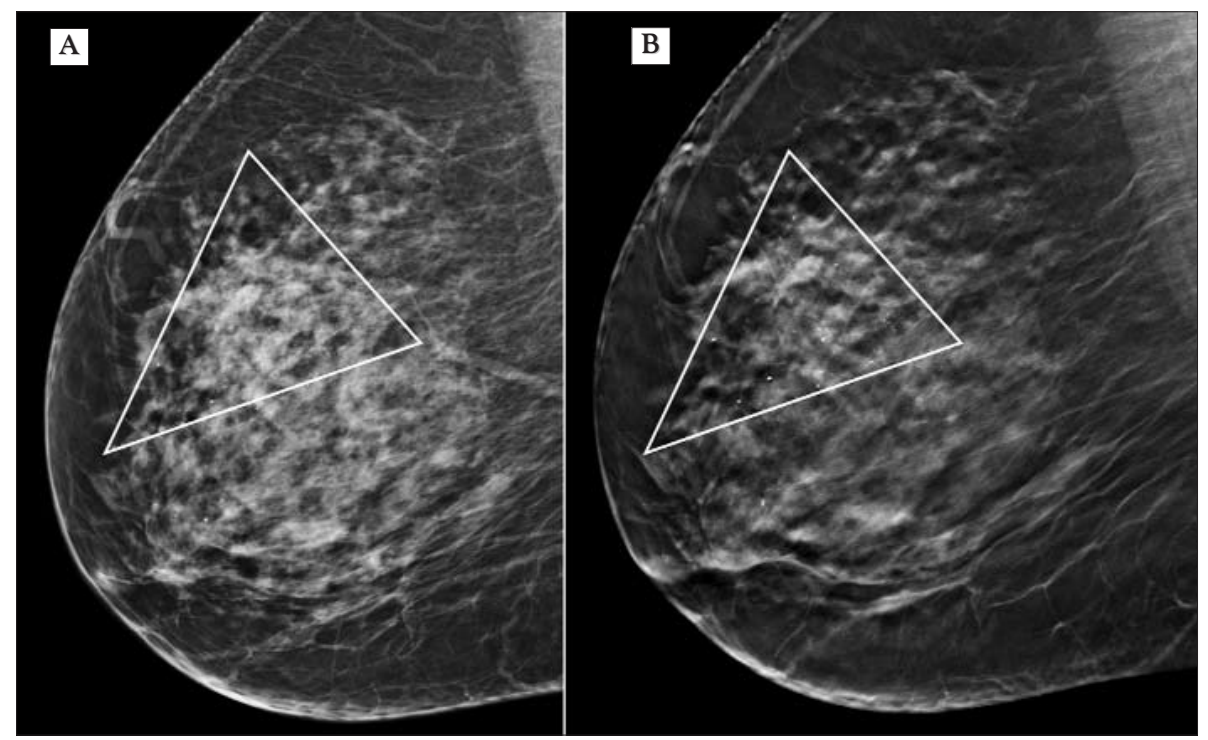

Figure 2. (A) Standard mammography shows punctate microcalcifications with segmental distribution (delimitated area). (B) Tomosynthesis slice where microcalcifications are better seen (delineatated area) 


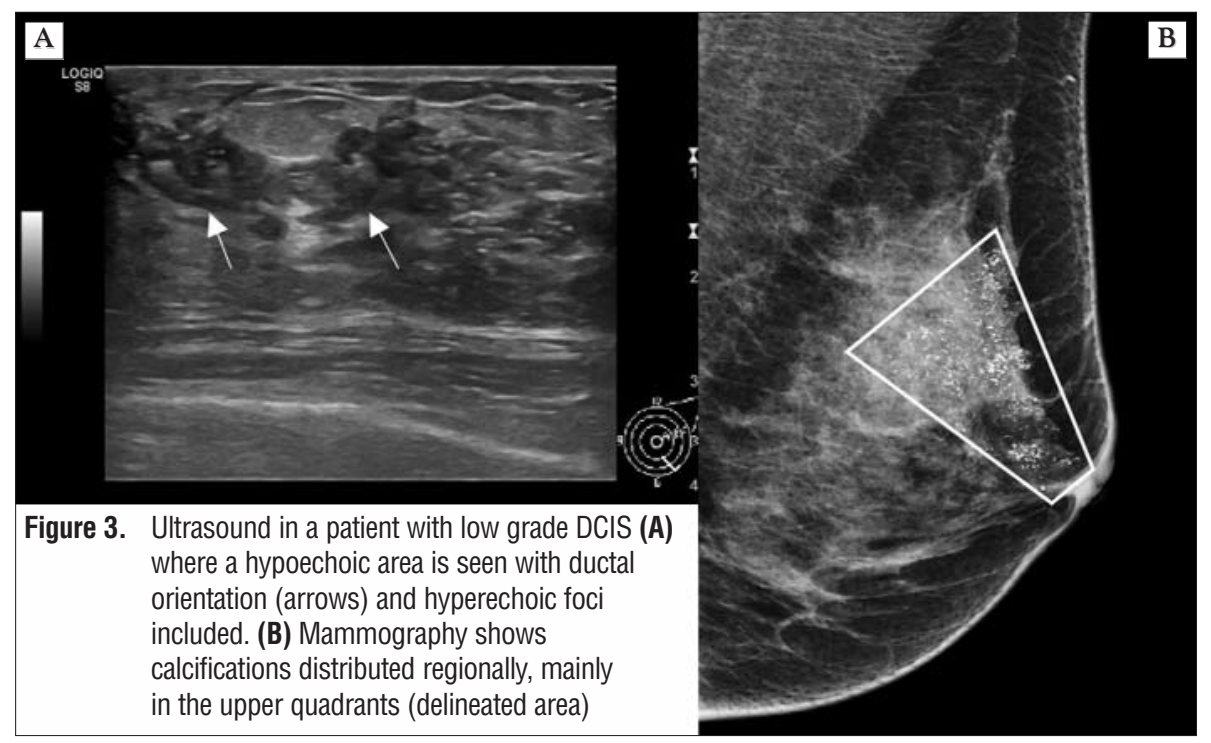

by solid masses $(28.0 \%)$ and duct abnormalities $(10.2 \%)$ or mixed masses $(8.1 \%)$. These hypoechoic areas (Fig. 3) are defined as non-mass lesions, somehow similar to the concept used in MRI when talking of non- mass enhancement. Kanako et al. (15) proposed an ultrasound examination algorithm which starts with the duct dilatations beyond the areola. If there is a focal dilatation beyond areola with floating internal echoes or isolated solid mass, then the aspect is considered to be very probable benign. The multiple solid irregular masses inside the dilated duct, or associating multiple echogenic foci, suggesting calcifications, should raise the suspicion for DCIS. If the dilatations are bilateral/multiple, or focal dilatation beyond the areola with anechoic content are present then the case is considered benign.

Ultrasound could be added when microcalcifications are seen on mammography in order to look for associated lesions, which could be easier to biopsy under ultrasound guidance. However, if hyperechoic foci suggestive for calcifications are seen on ultrasound, then an additional mammography should be performed in order to certify and characterize their shape and distribution.

There are not many studies to compare ultrasound tumour size assessments with mammography and MRI, in preoperative evaluation. Baek et al. (21) proved that ultrasound dimensions match with the pathological measurements, defined as a difference within $1.0 \mathrm{~cm}$, in approximately $77.8 \%$. This data suggest that ultrasound could be a useful tool in tumor size evaluation, although in our opinion it is too much operator and experience dependent to be reliable for surgical decision in all conditions.

\section{Magnetic Resonance Imaging (MRI)}

MRI is not the first-step method in the diagnostic of DCIS, because the lack of sensitivity in the detection of microcalcifications, which are the main imaging sign. However, MRI allows evaluation beyond the necrotic part of a DCIS manifested by microcalcifications, detecting the "living" proliferative part of the tumor process. This is due to its ability to detect regions with tumor angiogenesis, characteristic that seems to evaluate this method more appropriate for tumor size evaluation. Injection of the paramagnetic contrast media visualize, in DCIS, the regions where the permeability of basal membrane is increased by the pathological process, that could extend beyond the microcalcifications clusters. Therefore, MRI seems to be able to 
Figure 4. A 47-year-old woman with dense breasts (ACR D) and clusters of punctate microcalcifications in external quadrants of left breast evaluated BIRADS 4, seen with difficulty on mammography (A) are better seen on magnification (B). MRI MIP reconstructions (C) show a regional heterogeneous NME much more extended comparing with mammography (lower images). Histology: DCIS intermediate grade. Due to the high volume of the lesion, mastectomy was recommended
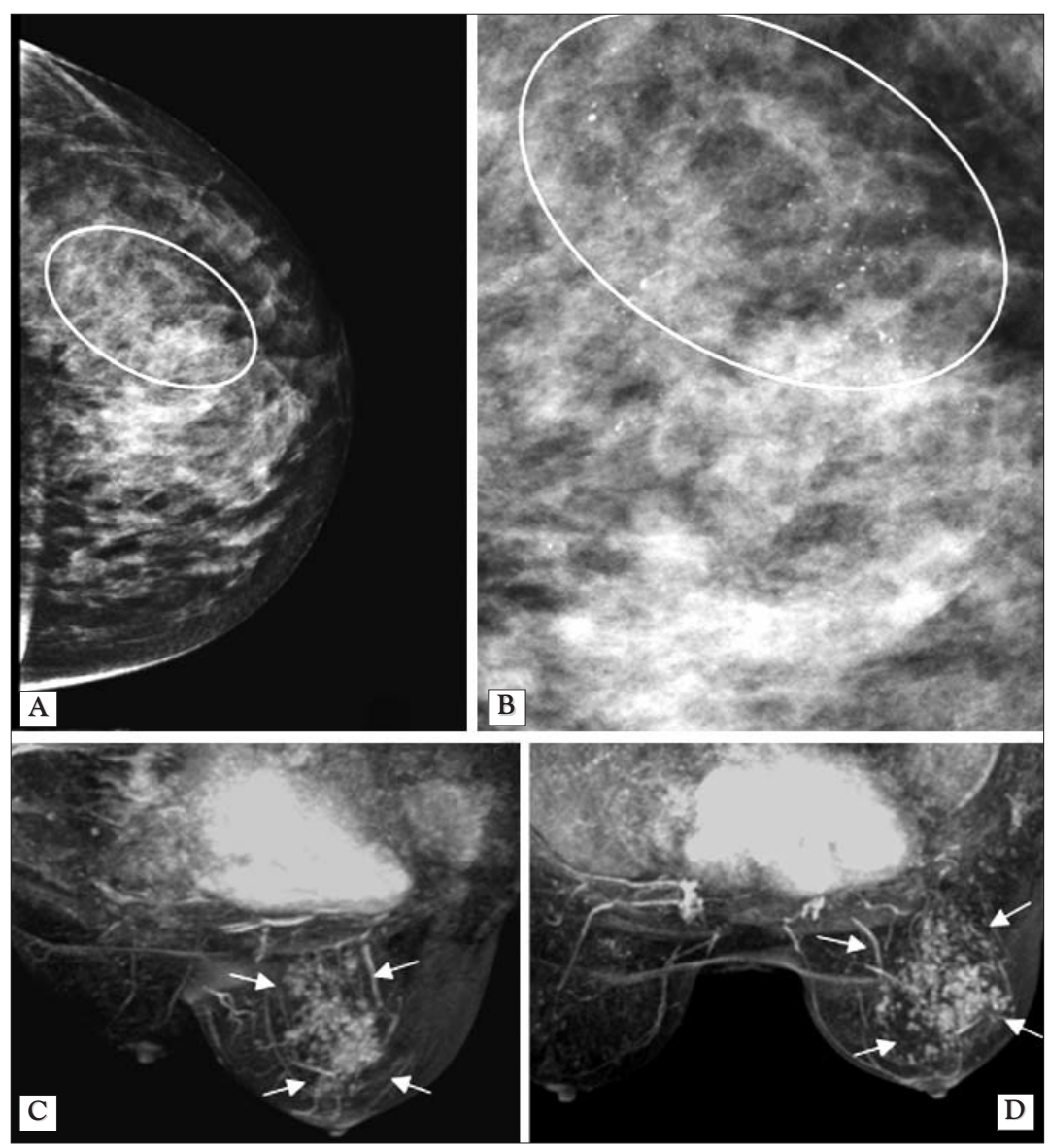

identify both calcified and non-calcified DCIS. The MRI presentation of DCIS is more frequently as a non-mass enhancement (NME), regional (Fig. 4), clumped, or ductal linear types. It can also present as masses of foci type of lesions. The kinetics is variable and more frequently it is a persistent type for NME lesions and plateau or wash-out type for masses and foci (16). The sensitivity of MRI is higher compared to mammography for highnuclear grade DCIS (22), so we expect to see more frequently on an MRI the high-nuclear grade rather than the low-nuclear grade DCIS.

The MRI examination is more useful in patients with dense breasts and suspicious calcifications. In these patients, who are usually less than 50 years old, the risk of underestimating lesion size using mammography is higher compared with fatty breast patients. When it is seen, the accuracy of tumor size evaluation for DCIS is better for MRI, ranging from $52 \%$ to $72 \%$, compared to mammography, where it ranges from $38 \%$ to $56 \%$ (17-20). MRI is expected to bring less information in patients with fatty breasts, where the calcifications with no other associated abnormalities are very visible and mammography is usually enough for the surgical decision.

\section{Conclusion}

DCIS is not, in the vast majority of cases, a clinically detected disease, so the imaging methods are essential for the diagnostic. DCIS is commonly detected by mammography, which remains the main diagnostic method. Ultrasound usually considered non-specific for the diagnostic of DCIS, could be a useful tool if we know to look for the appropriate signs. Therefore, in young women, where the ultrasound is the first-choice examination, the 
detection of hypoechoic regions with hyperechoic foci inside suggestive for calcifications should rise the suspicion of a DCIS. In these patients where calcifications are suspected on ultrasound, the mammography should be performed in order to certify and characterize the calcifications, regardless of the patient, taking into account that the mammography has a low energy irradiation. The MRI seems to be at this moment the best preoperative method for the evaluation of tumor size, especially in dense breasts as usually seen in young women.

\section{Reference}

1. Weaver D, Rosenberg R, Barlow W, Ichikawa L, Carney P, Kerlikowske K et al. Pathologic findings from the Breast Cancer Surveillance Consortium. Cancer. 2006;106(4):732-742.

2. Kerlikowske K. Epidemiology of ductal carcinoma in situ. J Natl Cancer Inst Monogr. 2010;2010(41):139-41.

3. Kerlikowske K, Grady D, Barclay J, Sickles EA, Eaton A, Ernster V. Positive predictive value of screening mammography by age and family history of breast cancer. JAMA. 1993;270(20):2444-50.

4. Ernster V, Ballard-Barbash R, Barlow WE, Zheng Y, Weaver DL, Cutter G, et al. Detection of ductal carcinoma in situ in women undergoing screening mammography. J Natl Cancer Inst. 2002;94(20):1546-54.

5. Mannu G, Wang Z, Broggio J, Charman J, Cheung S, Kearins 0 et al. Invasive breast cancer and breast cancer mortality after ductal carcinoma in situ in women attending for breast screening in England, 1988-2014: population-based observational cohort study. BMJ. 2020;369:m1570.

6. Salvatorelli L, Puzzo L, Vecchio G, Caltabiano R, Virzì V, Magro G. Ductal Carcinoma In Situ of the Breast: An Update with Emphasis on Radiological and Morphological Features as Predictive Prognostic Factors. Cancers. 2020;12(3):609.

7. Virnig B, Tuttle T, Shamliyan T, Kane R. Ductal carcinoma in situ of the breast: a systematic review of incidence, treatment, and outcomes. J Natl
Cancer Inst. 2010;102(3):170-8.

8. Badve S, Gökmen-Polar Y. Ductal carcinoma in situ of breast: update 2019. Pathology. 2019;51(6):563-569.

9. Tomlinson-Hansen S, Khan M, Cassaro S. Breast Ductal Carcinoma in Situ [Internet]. Ncbi.nIm.nih.gov. 2021 [cited 13 June 2021]. Available from: https://www.ncbi.nlm.nih.gov/books/NBK567766/

10. Rosner D, Bedwani R, Vana J, Baker H, Murphy G. Noninvasive Breast Carcinoma. Annals of Surgery. 1980;192(2):139-147.

11. Park T, Hwang S. Current Trends in the Management of Ductal Carcinoma In Situ. Oncology. 2016;30(9):823-831

12. Hofvind S, Iversen B, Eriksen L, Styr B, Kjellevold K, Kurz K. Mammographic morphology and distribution of calcifications in ductal carcinoma in situ diagnosed in organized screening. Acta Radiologica. 2011;52(5):481-487.

13. Barreau B, de Mascarel I, Feuga C, MacGrogan G, Dilhuydy MH, Picot V, et al. Mammography of ductal carcinoma in situ of the breast: review of 909 cases with radiographic-pathologic correlations. Eur J Radiol. 2005; 54(1):55-61.

14. Watanabe T, Yamaguchi T, Tsunoda H, Kaoku S, Tohno E, Yasuda $H$, et al. Ultrasound Image Classification of Ductal Carcinoma In Situ (DCIS) of the Breast: Analysis of 705 DCIS Lesions. Ultrasound Med Biol. 2017;43(5): 918-925.

15. Ban K, Tsunoda H, Watanabe T, Kaoku S, Yamaguchi T, Ueno E, et al. Characteristics of ultrasonographic images of ductal carcinoma in situ with abnormalities of the ducts. J Med Ultrason (2001). 2020;47(1):107-115.

16. Scott-Moncrieff A, Sullivan ME, Mendelson EB, Wang L.MR Imaging appearance of calficied and noncalcified DCIS Breast J. 2018;24(3):343-49.

17. Marcotte-Bloch C, Balu-Maestro C,Chamorey E, Ettore F, Raoust I, Flipo B, et al. MRI for the size assessment of pure ductal carcinoma in situ (DCIS): a prospective study of 33 patients. Eur J Radiol. 2011;77(3):462-7.

18. Kim do Y, Moon WK, Cho N, Ko ES, Yang SK, Park JS, et al. MRI of the breast for the detection and assessment of the size of ductal carcinoma in situ. Korean J Radiol. 2007;8(1):32-9.

19. Shiraishi A, Kurosaki Y, Maehara T, Suzuki M, Kurosumi M. Extension of ductal carcinoma in situ: histopathological association with MR imaging and mammography. Magn Reson Med Sci. 2003;2(4):159-63.

20. Schouten van der Velden AP, Boetes C, Bult P, Wobbes T. The value of magnetic resonance imaging in diagnosis and size assessment of in situ and small invasive breast carcinoma. Am J Surg. 2006;192(2):172-8.

21. Baek SH, Choi WJ, Cha JH, Kim HH, Shin HJ, Chae EY. Comparison of mammography, ultrasound, and MRI in size assessmentof ductal carcinoma in situ with histopathologic correlation Acta Radiol. 2017:58(12):1434-41.

22. Kuhl CK. Why do purely intraductal cancers enhance on breast MR images? Radiology. 2009;253(2):281-283. 